\title{
Walking in the City of Signs: Tracking Pedestrians in Glasgow
}

\author{
Salmiah Abdul Hamid \\ Department of Architecture, Design and Media Technology, Aalborg University, Aalborg, Denmark \\ Email: salmiah@gmail.com
}

Received 24 July 2014; revised 20 August 2014; accepted 17 September 2014

Copyright (C) 2014 by author and Scientific Research Publishing Inc.

This work is licensed under the Creative Commons Attribution International License (CC BY). http://creativecommons.org/licenses/by/4.0/

(c) (i) Open Access

\begin{abstract}
This paper aims to determine the way in which materialities within the environment influence pedestrians' movements when searching for signs. The use of mobile methods to observe and track human interactions with the signs in a city contributes to the empirical data collection on everyday life practices of this study. This article presents the findings from non-participatory observations conducted in Glasgow. The observations took place in a selected area to explore the natural behavior of pedestrians in urban spaces when searching for signs. Random pedestrians were "unobtrusively" followed to investigate their natural pattern behavior when choreographing their travel flow. This study helps to determine the advantages and disadvantages of mobile methods for investigating the relationship between pedestrians, materials and the environment. The interdisciplinary approach developed in this article presents new perspectives on the way mobility and geosemiotics could contribute both theoretically and empirically with new knowledge in design practices.
\end{abstract}

\section{Keywords}

Pedestrians, Non-Participatory Observation, Signs, Tracking Pedestrians, Mobile Methods

\section{Introduction}

In a previous study by Hamid, Jensen and Andrade (2012), the authors discussed the importance of choreographing travel flow from above (policies and common traffic signs regulated in urban spaces). The authors also suggested that there are layers of communication between people, the city, as well as cultural and social signifiers of the materialities in place; practices relating to the creation of sign systems for directing mobility become much more than simply a question of regulatory frameworks, traffic safety or highway engineering. The semiotics affording particular movements become important cultural and social signifiers that create the communica- 
tive layer of the city, and thus, ultimately, the way we engage with the world (Hamid, Jensen, \& Andrade, 2012).

Have you ever walked in your hometown in search of a new restaurant suggested to you by your colleagues? How do you get there if you are planning to walk? Fundamentally, you might ask your colleagues for directions or "Google" the locations on the Internet. In search of your destination, you might be overwhelmed by the multitude of existing "signs". The existence of "a constituted place of sign system space" (de Certeau, 1984) becomes increasingly accepted in mobility research and urban planning. I would suggest that users of the semiotic environment use different approaches to move about. This paper, which was conducted between March-April 2012, looks into several aspects of walking in a city.

The area of study was Glasgow city centre. Glasgow is the UK's "largest retail centre" outside London and is Scotland's largest city (Factsheets, 2012). The "pedestrian volumes" (Whyte, 1994) in Glasgow are higher than in the capital city of Scotland, Edinburgh. Given the large geographical scale of Glasgow, there are more activities in the city centre such as shopping or arts and cultural performances. In terms of the urban context, Glasgow is very "pedestrian-friendly". Therefore, most of the pavements are very broad.

In mobility research, both social practices and the environment play important roles in human daily life. This paper examines pedestrian mobility in the real "material world" (Scollon \& Scollon, 2003) through a mobile ethnography method. Büscher and Urry (2009), in their study of "Mobile methods in the empirical", illustrates how important it is that the researcher adapts or experiments with new techniques to observe and record social settings. Therefore, this study also emphasizes the exploration of "mobile technology" and non-participatory observation to document pedestrian journeys in the observation area.

In this study, the empirical investigation into how signs influence human mobility in an urban environment was conducted through tracking pedestrians' routes on foot (Hill, 1984; Lee \& Ingold, 2006; Van der Spek et al., 2009). As mentioned by Lee and Ingold (2006), walking is a "phenomenologically inspired fieldwork practice" compared to symbolic analysis commonly designed for traditional ethnography. In a study conducted by Millonig et al. (2009), the authors suggested that "In non-participatory, unobtrusive observations the researcher follows the subject at a distance, recording her movements by drawing a line corresponding to the subject's activities on a map of the investigation field" (p. 32). The authors also illustrated the advantages and disadvantages of pedestrians' "natural" behavior from this method of study. In this study, the investigation particularly focuses on the pedestrians' movement within the urban spaces. The research question tries to unfold the meaning of visible signs in urban spaces which are used by pedestrians when navigating the cityscape. This paper has two main objectives. Firstly, the study investigates how pedestrians behave when searching for directions in urban spaces. Secondly, this study explores the mobile methods applications used for tracking pedestrians' movements.

The paper is structured as follows. The next section introduces the theoretical framing of urban walks in terms of the rhythm of walking, signs in the city and the moving body. This is followed by a discussion of mobile methods and the data analysis obtained from the observation of pedestrian behavior in Glasgow. The paper concludes with a discussion of the limitations of mobile methods as well as suggesting future research on the cognitive understandings of "why" human behave and react to the signs or physical elements the way they do.

\section{Framing Urban Walks}

This section presents the theoretical framework which shapes our understanding of walking. Here we are working within the mobilities turn (Cresswell, 2010; Sheller, 2012; Urry, 2007). Importantly we link the basic understanding of mobility to the notion of "geosemiotics" coined by Scollon and Scollon (2003) in order to create an analytical framework which is sensitive to bodies in motion as well as sense making and interpretation of the semiotic environment.

\subsection{The Rhythm of Walking}

As suggested by Solnit (2001), walking is a dynamic process that humans think while they are walking at the same time. All human beings have a different rhythm of movement when they drive, walk, cycle, run, etc. However, as pedestrians, humans are directly involved in the environment and react to what they see, hear and touch. Halprin (1963) suggested that the speed and motion of pedestrians vary according to their senses and rhythm of walking within the built environment. Whyte (1994) on the other hand, argued that a pedestrian is part of a "social being" (Knox \& Pinch, 2006), since no pedestrian can walk without being part of the environment at the same time. A person who walks is also "a transportation unit" but without the wheels or the steering to ma- 
neuver the movement of a vehicle in the streetscapes. The way a pedestrian navigates within a space depends on the complexity of the space and how the pedestrian understands the space (Whyte, 1994).

As pedestrians, we have to decide which path or route we are going to take when we walk in urban settings. Sometimes, we might purposely choose the scenic route, walk past buildings that we are familiar with or decide to take the shortest route to our destination. Whatever the reasons behind our choice of route from point A to B, we will always see different things as we travel. Cullen (1961) discusses the "serial vision" which means that "the scenery of towns is often revealed in a series of jerks or revelations" (p. 11). We now turn to the signs in place which are viewed while walking in the city.

\subsection{Signs in the City}

In a study by Crundall and Underwood (2001: p. 188) on the "priming function of road signs", the authors concluded that "the UK road system often employs the repetitive use of road signs on the run up to a single hazardous road feature". In current urban scenarios, urban streetscapes are embodied with a linguistic landscape which includes not only signs to regulate traffic users but also advertisements, posters, notices, street names, wayfindings, as well as shop signs. In our daily life, traffic signs are important guides helping pedestrians, motorists and cyclists to avoid accidents. Borowsky, Shinar, \& Parmet (2008: p. 1) suggested that "misplacing objects—specifically, traffic signs at intersections - can be a potential hazard to experienced drivers who fail to identify them". However, Fauque (1986) argued that motorists and pedestrians have different perceptions when using traffic space according to differences in the "flow of visual and auditory images". Drivers for instance took note of "pedestrian zone" street signs to avoid collisions with pedestrians. Thus, the regulated traffic sign prohibits motorists from entering the zone. On the other hand, the massive placement of traffic signs affects the driving performance of motorists as they can be distracted by cluttered signs (Edquist, 2008a) placed on streets. Pedestrians usually have more time to navigate within urban spaces in contrast to vehicle users. However, pedestrians do not search for street signs that are not relevant to them as the majority of traffic signs in urban spaces regulate vehicles. We now turn to how pedestrians move within the space to look at the performance of pedestrians within urban spaces.

\section{The Moving "Body" vs. Moving through "Spaces"}

With respect to the performance of pedestrians when walking in the streets of an urban space, orientation is one of the important elements that help to ease the movement of embodied travel. Orientation is defined by Rapoport (1977) as a combination of "physical elements" and "socio-cultural rules". According to Baers (Rapoport, 1977: p. 148), there are four main methods of orientation; (i) Signs and verbal aids (asking); (ii) Recognition of pattern of location; (iii) Habitual patterns of behavior and; (iv) Landmarks.

The city and other elements within the built environment influence pedestrians' movement and orientation. Duff (2010) suggested that "To walk is to be affected by place and to simultaneously contribute to the ongoing co-constitution of self and place” (p. 7). Therefore, pedestrians' behaviour depends on the individual's preferences regarding moving between spaces be they familiar mundane spaces or more meaningful spaces that bring back memories of particular places. As mentioned by Casey (2001), "The vehicle for being-in-place is the body" (p. 413) and therefore the human mind and body play important roles in determining the destination. As Jensen argues:

The mobile body is the entry point to understanding the individual's engagement with the world as well as it is the key to seeing the way meaning and norms are created in embodied cultures of mobilities (Jensen, 2013: p. 119).

Understanding bodily movement in urban spaces helps us to better understand social practices. As argued by Scollon and Scollon (2003: p. 182), pedestrians only refers to signs regulated them to walk instead of the legal markings on the pathways. How does a person navigate, orientate and make sense of this at times overwhelming milieu? This question has been articulated by scholars before us, e.g. Georg Simmel in his seminal essay "Metropolis and Mental life" (Simmel, 1950) where he argues that the senses are over stimulated and thus that the modern urbanite (1880s Berlin that is) reacts with a famous "blasé" attitude. Most urban dwellers who walk along the same streets in their daily lives tend to be more inattentive of their surroundings. They may ignore the elements in the built environment such as traffic signs, street signs, or even advertisements posted on traffic lights. Such analysis seems to still be highly relevant but here we shall turn our analytical attention from the in- 
teraction and communication between mobile urbanites towards the individual and his/her attempt to navigate and make sense of the city and its semiotic layers. Next, an exploration of mobile methods inspired from Büscher, Urry and Witchger (2011) was carried out in the study areas to track the movement of pedestrians, through field notes, as well as still and video documentation using digital devices such as an iPad and DSLR camera. These explorations provide practical mobile ethnography methods that could contribute to the empirical study within the social sciences and urban design when looking at the interconnections between objects-environment-people.

\subsection{Mobile Methods}

In mobilities research, numerous empirical data methods are used to unpack everyday life practices. A previous study by Büscher, Urry and Witchger (2011: p. 7) presented ten practical mobile methods that can potentially be used to "capture, track, simulate, and mimic" the pedestrians' natural behavior within the urban spaces in search for their destinations. The next section presents a more detailed discussion of the study's empirical data collection process.

\subsubsection{Tracking the Pedestrian}

This section introduces the method of observing pedestrians' travel behavior within the selected urban spaces. In previous studies which tracked pedestrians, the researchers used GPS to track the movement of pedestrians or visitors (Shoval, 2008; Van de Spek, et al., 2009; Pettersson \& Zillinger, 2011). However, the aim of this empirical study is to observe, analyze, and explain the relationships between signs in the urban spaces and pedestrian behaviour.

In 1984, Hill published a paper in which he described the comparative study of questionnaire techniques vs. tracking urban pedestrians' behavior in large-scale environment behavioral mapping. In my study, I adopted the "completed observation" point based on Hill's suggestion from which the subject arrived at the final location or the subject was idle for more than ten minutes at one place to avoid tracking the pedestrians for long period of time. This is however open to question as it depends on how the researcher observes the subjects within the selected area of study. In this study, the exploration of "on foot observations" was performed based on the tracking research conducted by Hill, observational methods from the geosemiotics approach adopted by Scollon and Scollon (2003) and mobilities practices conducted by Büscher, Urry and Witchger, 2011; Jensen, 2010a; Sheller and Urry, 2006.

This paper presents the results of field observations conducted in Glasgow, Scotland in March 2012-April 2012. The study applies the multi-methods in gathering data through observations as well as the behavioral mapping of pedestrians. Hill (1984) illustrated "behavioral maps" as an "observed behavior" within an environment. Thus, this study focuses on the performance of the pedestrians through the eyes of the researcher. As part of the mobile methods of investigation, the "mobile iPad" is used for field note taking, mapping movement, capturing photos as well as video documenting. However, since the iPad is a relatively new tool for collecting and documenting data, it has limited functions and capabilities. Thus, this tool was also used as a "time-space diary” as mentioned by Büscher and Urry (2009) which "can be textual, pictorial or digital or some combination" (p. 105) and which can also track pedestrians' movement with the help of GPS. This section consists of different investigations conducted at the location which emphasize the context, the study area, the instruments, participants and procedures used when investigating natural pedestrian behavior in city settings.

\subsubsection{Research Area}

The research area for this study includes the flow of pedestrians, the streetscape designed for pedestrians as well as the road signs within the perimeter of the urban context study. Therefore, in order to conduct the ethnographic investigations of how humans move within an urban cityscape, it is important to document people's reactions or human behavior towards the materials in place such as the road signs. In order to do this, the researcher documented most of the daily observations using the "penultimate" app on the iPad which allows one to write and include pictures at the same time. This is a very useful tool that can be used by ethnographers who wish to write down everything they see and hear with a single tool.

There are three main pedestrian areas in Glasgow city center (Figure 1). The highest pedestrian flow is in Buchanan Street where most of the main attractions such as shops and theatres are located. The average pedestrian flow area is located in Argyle Street which also includes expensive boutiques and shopping centers. The 


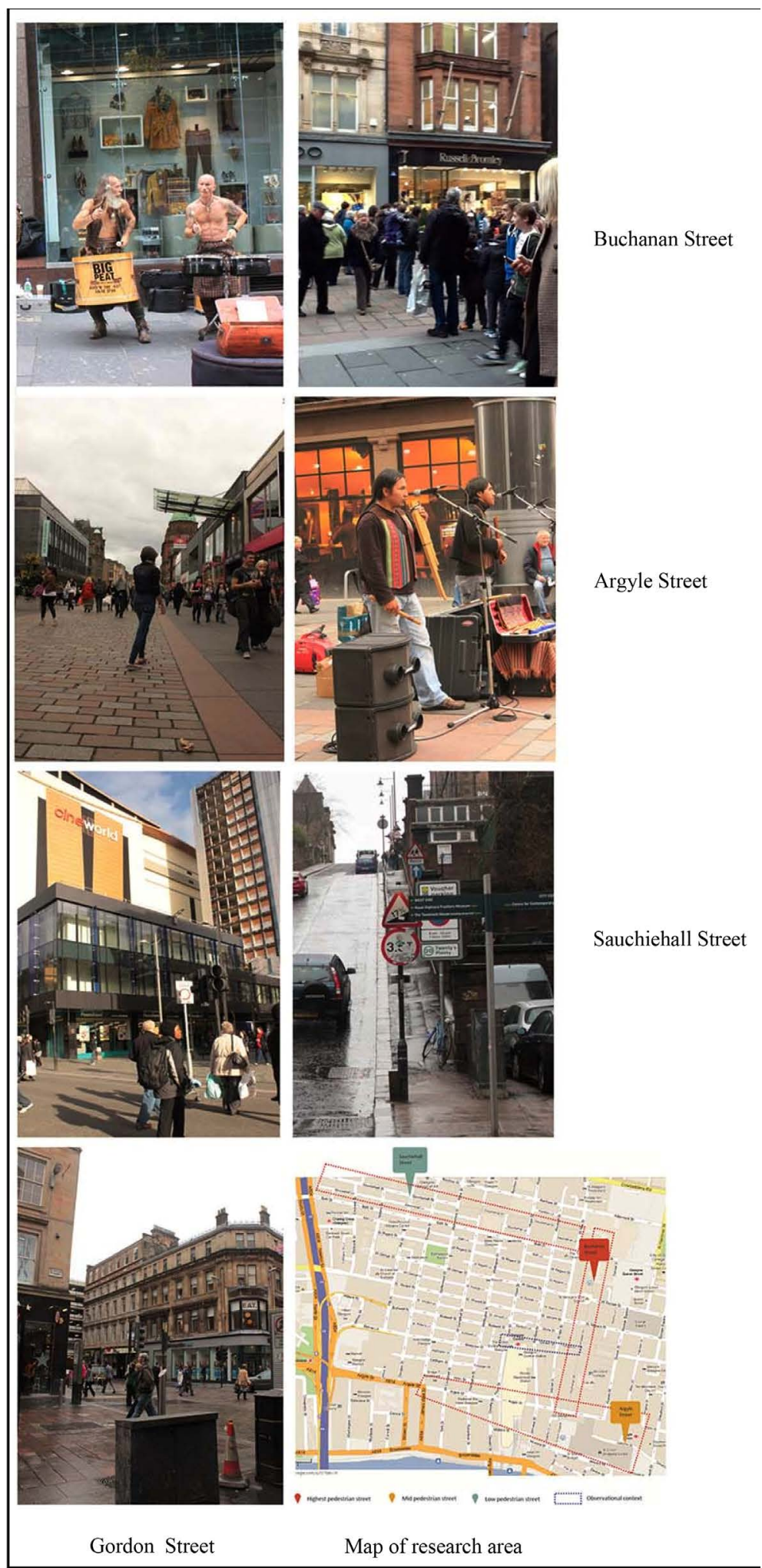

Figure 1. Glasgow pedestrian street.

lowest pedestrian flow is in Sauchiehall Street. However, Gordon Street is selected as the research area since it is considered to be the nearest street that is connected to other three main pedestrian shopping streets indicated 
before. Besides that, the street is close to the Central Station which is commonly used by locals or foreign travelers when travelling from Glasgow to other places outside the city.

\subsubsection{Research Instruments}

The tracking tool used was an iPad which was used to experiment with several free and paid-for applications for tracking, note taking, as well as audio-visual recording. The mapping tool used for tracking the movement of pedestrians from point A to point B was tested in terms of tracking the route and converting it into a "tracked map”. Additionally, a DSLR camera and the iPad's embedded camera were used to take pictures of signs and the individual's behavior towards the signs in order to illustrate the relationship between the map and the participants' socio-economic and lifestyle status. Some pictures that are used in this paper had few marks and notes or drawings edited in the "Penultimate" application on the iPad which indicated that note taking and capturing the real situation of the targeted pedestrians can be done in "real-time" on digital device.

\subsubsection{Participants}

The participants were randomly selected and could be single pedestrians or individuals walking in groups. The participants selected were diverse in terms of gender, age and ethnic background (locals or foreigners unfamiliar with the urban spaces). The participants who were tracked during this study were selected randomly from 10 different individuals/groups. However, in this paper, I will only discuss two of the tracked individuals.

\subsubsection{Procedure}

As part of the non-participatory observation, the researcher had to stand on street corners within the perimeter of the study and observe people's behavior. Based on the observations, some of the individuals referred to the city map on the street in order to reach their destination while others used their mobile phone or printed map to search for their destination. Some of the travelers also asked other pedestrians the way to the Central Station which is located just one block away. As I was walking in the study area in Gordon Street, I noticed that the sign for the Central Station was not easily visible to pedestrians. This is one of the reasons why most pedestrians who were not from the area had difficulty finding the central station. This also supports the four orientation methods by Baers (1966) in Rapoport (1977) as previously mentioned. Bechtel and Zeisel (1987) define behavioral mapping as the interaction between human behavior and space and time. In order to track pedestrians' movement from point A to B, the mobile tracking software "Road Tripper" on the iPad was used. As well as tracking movement, images of visible road signs are captured along the way (Figure 2(c)). Several other apps were used and experimented with in the study in order to find the best for collecting in situ data. However, most of the maps available on Google Street Map were updated two years ago. Therefore, the maps had to be updated manually through observations.

\section{Data Analysis and Experiences}

Based on the observations and tracking conducted, it can be argued that most pedestrians considered few important elements when searching for directions. The elements that they normally looked at included street names, street maps, and also street signs for locations. Next, the paper discusses the empirical evidence into three main categories of findings which emphasized human behavior, materialities, communication and mobile search. The empirical findings were obtained through field data such as photographs, tracked maps, and field notes.

\subsection{Human Behavior in Urban Streetscapes}

The urban streetscapes are composed of street furniture such as traffic signs, advertisements, traffic lights, the pavement between vehicles and pedestrians, as well as street lighting. In the streets of Glasgow, the effects of pedestrians' social behavior can be seen through their actions and interactions with the elements in the built environment. The interaction between the pedestrians and the "materials in place" in Figure 3 shows that even though the lights say "stop", the pedestrians still crossed the road. Even though crossing the road when the red light is on is not an offense in the UK, it is subject to a fine in other countries such as New Zealand and Australia. This also supports what was argued by Whyte in 1988 that people in cities like Boston and Montreal tend to cross the street when they feel safe without paying attention to the color of the traffic lights. During this study, most pedestrians gazed at cars and some gazed at others who crossed. The traffic lights function as an indicator 


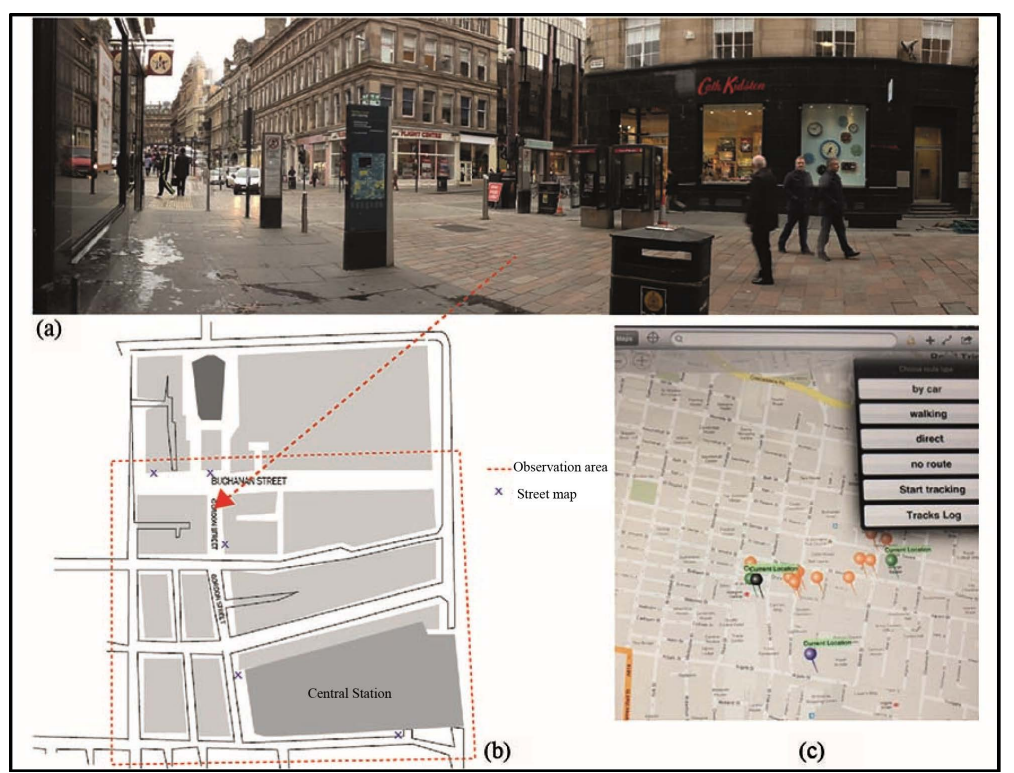

Figure 2. (a) View from the Observation location captured using the iPad. (b) Tracking pedestrians context of observation (c) screenshot of road tripper app for tracking pedestrian routes.

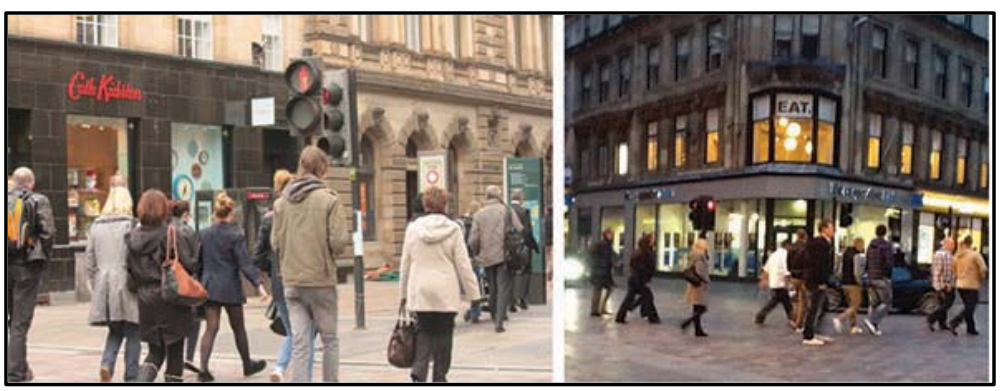

Figure 3. "Red light” crossings between mid-afternoon and evening.

for drivers to be more careful with the coming pedestrians at the intersections. Thus, the pedestrians negotiate the spaces also according to other objects that were not present at the particular time (other vehicles and not the red light). As argued by Jensen (2010b), people negotiate spaces as part of their social interactions in their everyday life. And as mentioned by Carmona et al. (2010), urban streetscapes are considered mental constructs which are commonly interpreted and valued differently by individuals. Thus, in reference to Lynch (1960), Carmona et al. also reflect that the crossing routes in urban spaces are considered the key nodes of cities.

\subsubsection{Materialities and Communication in Place}

Street map signs are the most important element in Glasgow to guide pedestrians to specific locations in the city centre. As argued by Vertesi (2008), maps serve as a "device" or a material for interactions between the pedestrians and the environment. The street maps are appropriately placed on the sidewalks in the pedestrian zones. In terms of gender, females spent more time reading the street maps compared to men. In the observation area located at Gordon Street, there are fifteen (15) traffic light signals, two (2) street maps, nine (9) regulatory signs and one (1) mixed regulatory and informational sign. Based on the observations through field notes, photographs and video recordings, most of the pedestrians searched for locations by looking at the street names (located on the corner of buildings) or by looking at the map or landmark buildings. However, in terms of the regulated traffic signs, most of the pedestrians were not obliged to follow the signs even though the signs are placed at the pedestrian zones.

The materialities in place are also very significant for the geosemiotics analysis (Scollon \& Scollon, 2003). 
The size of street signs, advertisements or stickers on regulated traffic signs affects the traveling behavior of pedestrians if they are not looking for specific signs when they move in the urban spaces. As can be seen in the Figure 4(a), a number of Glasgow City Council's regulated traffic signs had been tampered with posters or stickers. The road traffic signs were also not "respected" by the road users as the signs were used to park their bicycle (Figure 4(b)). As for people who are familiar with their route and surroundings, they will certainly not pay attention to traffic signs which are considered irrelevant. However, pedestrians who are unfamiliar with the route will refer to specific visible cues such as buildings, signs or verbal aids from others. Next in turn we look at how pedestrians communicate in urban spaces when way finding.

As argued by Scollon and Scollon (2003), it is human nature to communicate and interact with living or non-living things. In this context of observation, some of the pedestrians, either locals or people from outside Glasgow, interacted with other people when searching for the "Central Station" which is just around the corner. The street map provides directions to the central station but since the font used is rather small, senior citizens tended to ask people around for directions instead. Hand gestures and conversations between the "lost person" and "guide person" played a very important role especially when senior citizens were involved. Therefore, as can be seen in Figure 5 below, even though there is an informational sign nearby, it seems like "asking" is a more reliable and faster way of getting the required information apart from searching or looking for signs.

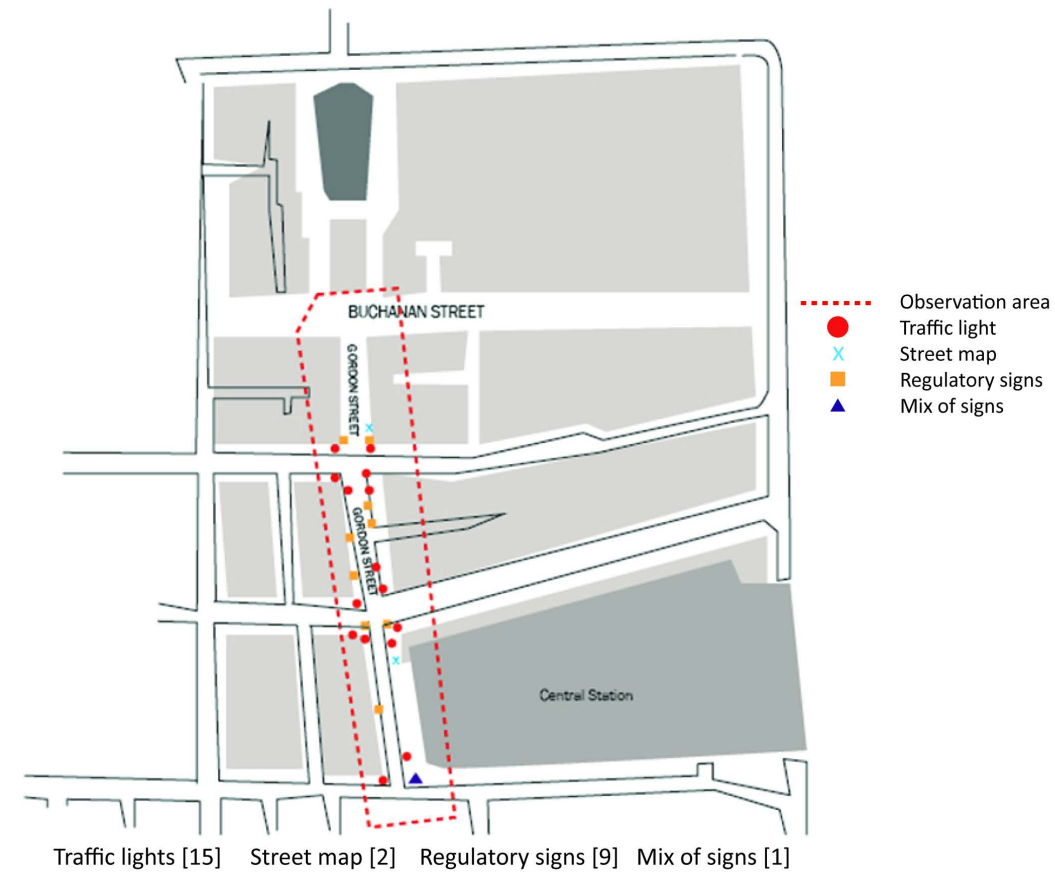

(a)
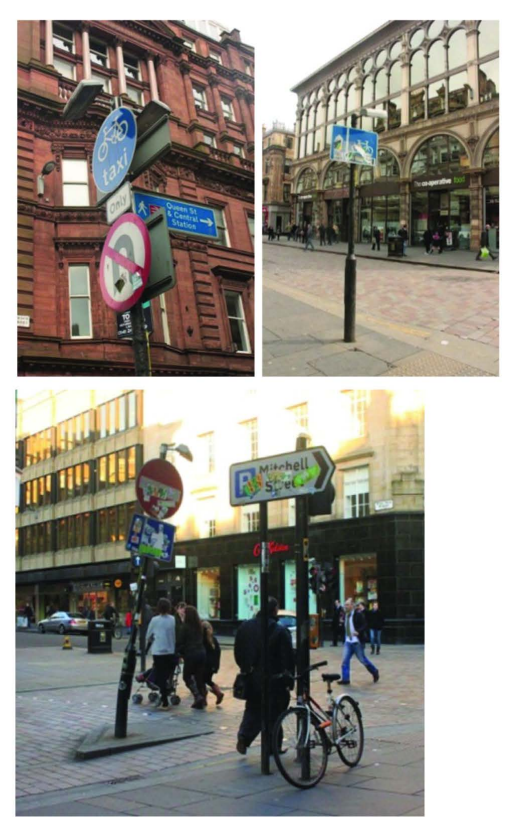

(b)

Figure 4. (a) Locations of "traffic signs" in the observational area (b) Images of signs located on Gordon Street.
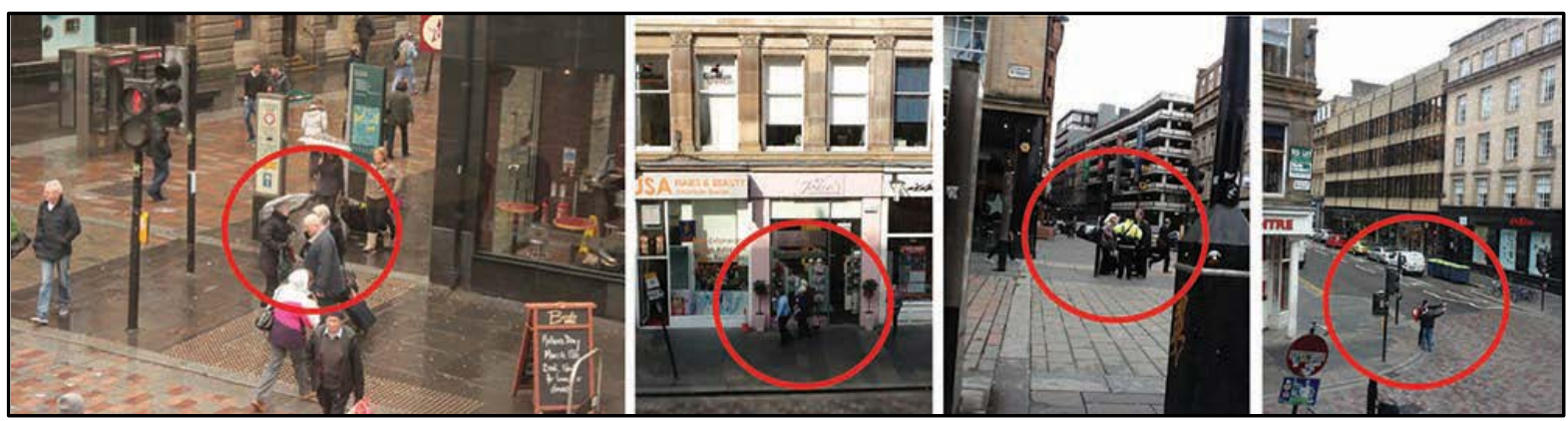

Figure 5. Senior citizens asking for directions. 
The observations were also conducted from the top of a building to get a different perspective of how the pedestrians orchestrated their travel behavior when searching for directions. These findings of observing the natural behavior of pedestrians from a distance inspired from the previous study by (Whyte 1988) who unobtrusively observed people without affecting their routine behavior. As mentioned earlier, this study not only unfolds the theoretical aspects of research in building block of materialities in urban spaces but also the empirical data tools that help to understand the interweaving of empirical methods in geosemiotics and mobilities. In contrast to earlier orientation methods in the introduction text by Rapoport (1977), the pedestrians in this study tended to look at signs (street maps) or resort to verbal aid (asking for directions) in order to find their destination. Li (2006) in his investigation of way finding suggested that route knowledge is an important factor when moving from one place to another and it includes "procedural descriptions, some landmarks and path elements".

In my research findings in this study, some of the pedestrians not only looked at the street maps, but they also asked other pedestrians for directions after they had looked at the maps, and tried to find their current location on the map by looking at buildings and street names. Even though Rapoport theoretical aspect of orientation is old, the human mind and perception of space remains the same according to individual cognitive mind mapping. Thus, with the emergence of mobile technology and location-based systems, we look at the importance of mobile technology regarding pedestrians and the mobile method used to track the pedestrians' behavior in the next section.

\subsubsection{Mobile Technology vs. Street Map Search}

Mobile technology vs. street map search in the context of this study means the use of devices or tools to search for specific destinations by the pedestrians. In order to obtain a better view of the movement and more accurate journey mapping, mobile applications on the iPad were used to track pedestrians' journeys from point A to point $\mathrm{B}$ and a digital camera (DSLR) was used to capture the movement of the pedestrians who were unfamiliar with the areas. As suggested by Büscher (2006), "By engaging carefully with the actual, moment-to-moment production of professional vision, it is possible to begin to understand the specifics of the practices involved" (p.297).

During her search for her destination from the train station, a lady with luggage used her mobile phone to search for directions from the station to " $\mathrm{X}$ ". The lady seemed to be totally unfamiliar with the area since she stopped at a few places on the street to look at her mobile phone and the street map. However, it was hard to determine whether the woman was purposely looking for the information centre or asking for her specific destination. The most important aspect of knowledge here is that even with advanced mobile technology; sometimes a person needs to make sense of the place to become more familiar. It is a decision making process and knowledge structure of "cognitive representation" or "cognitive map" (Golledge \& Stimson, 1997). Thus, the lady seemed to be finding her own way by following her technology based information (mobile phone), her sense making of landmarks and looking at the street map, which may have helped her locate her actual destination (See Figure 6).

With regards to a more challenging and time consuming behavioural mapping of pedestrians, the "Men in suits" tracking observation was relatively thought-provoking in terms of the way they navigated within the city spaces. During this study, two men who were selected randomly, started their journey at the shopping street near Bu-chanan Street and ended up at Bothwell Street. After almost 40 minutes of trailing the men, the researcher had some interesting experiences and collected data from the tracked map using the Road Tripper application on the iPad. The travel journey and visual data obtained through the observation is as follows:

An excerpt from the researcher's field note diary;

After almost 40 minutes of walking, they end up at a restaurant. Before that, they went into shops and build ings to ask for directions [my assumption anyway]. Even though the weather was really hot, they never seemed bothered by the weather and still laughed and engaged in normal conversation without becoming anxious. They also looked at buildings and street signs for landmarks. Most probably the address is not in their GPS settings [thoughts in the author's head at the moment] after almost an hour of trailing the men insuits (researcher Diary, 29 March 2012 at $12.45 \mathrm{pm}-1.33 \mathrm{pm})$.

Solnit (2001) suggested, "passage through a landscape echoes or stimulates the passage through a series of thoughts". Even though the researcher's attention was on tracking the movement of the "men in suits", the researcher had lots of thoughts in her mind about whether the "men in suits" were lost and had ended up in a restaurant due to frustration over not finding their actual destination or whether they had finally found the place. As mentioned by Vannini (2012), performances rely on movement and it seemed that the "men in suits" enjoyed their walking as they could still laughed despite their long and tiring journey. If we refer to Figure 7, Map of 


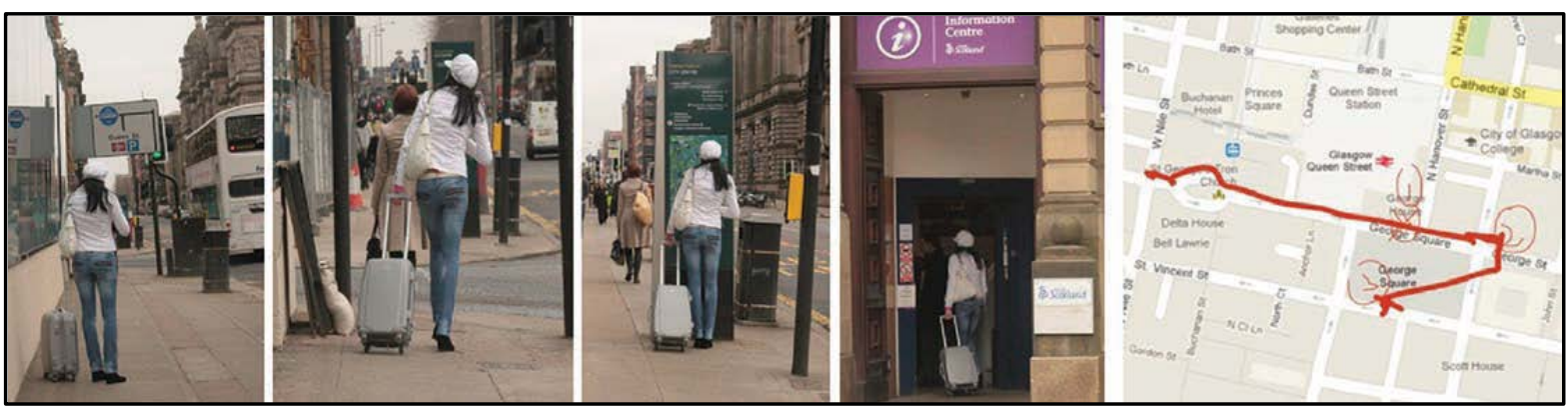

Figure 6. A woman's sequence of movement and the tracking map (indications of 3 stops).

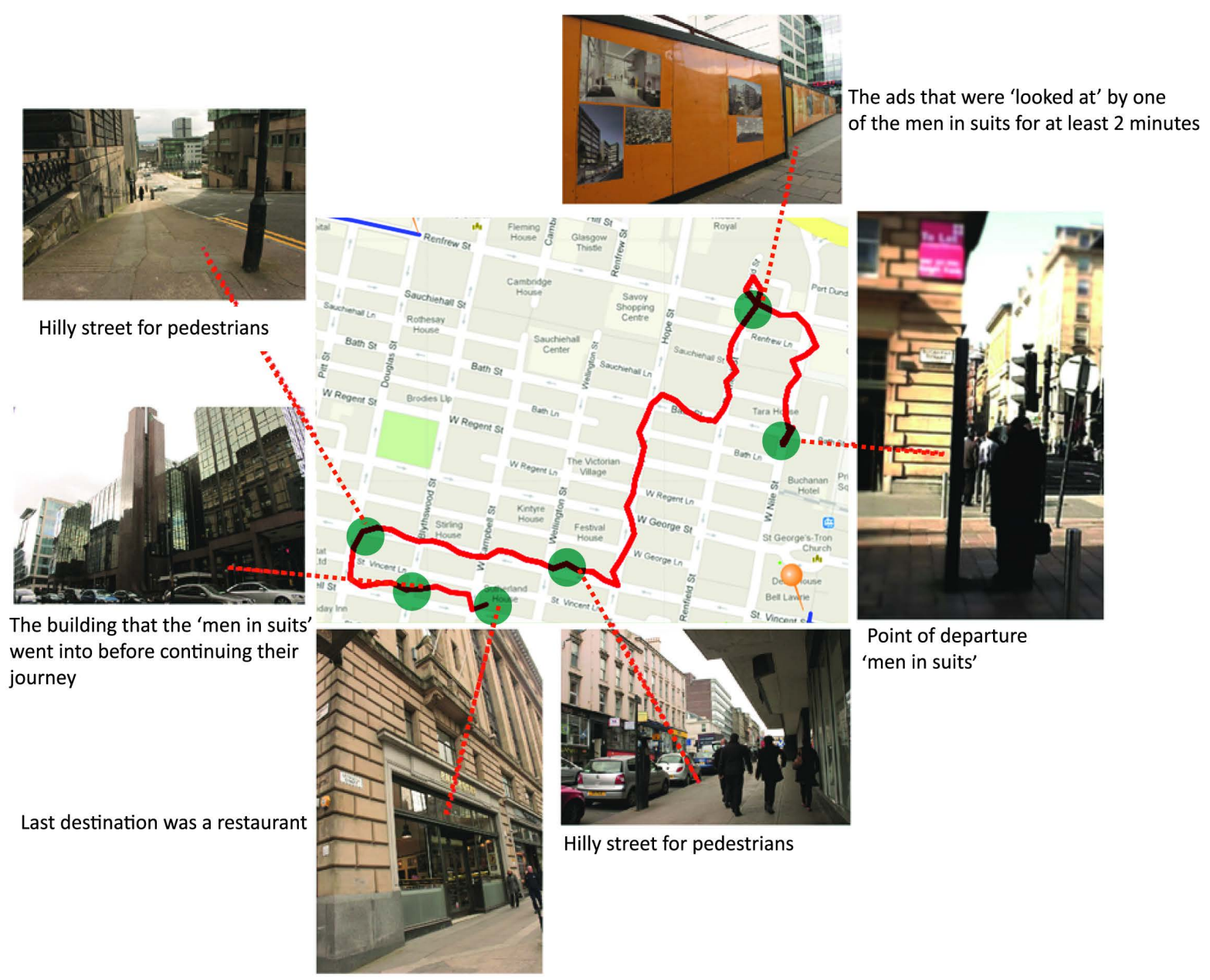

Figure 7. Map and photos of "Men in suits" trail from the street map location at Buchanan Street to end destination.

"Men in suits" trail, both men had difficulty in finding the exact location of their destination. Even though there were street maps and street signs on street corners, they became lost. However, in terms of their performance in movements, they seemed to be very calm since they did not have any arguments along the way. In other words, sometimes not everyone is patient when trying to find their way. This definitely is not considered as a "blasé attitude” since they were both unfamiliar with the urban spaces and this unfamiliarity affected their travel flow.

Despite all the observations and tracking the bodily movement of pedestrians in Glasgow, there is still a gap in terms of the cognitive understanding. How do we know that they understood the meaning of the signs in relation to the street maps, or whether there is a lack of informational guidance on the street which if present could ease the pedestrians' journey and destination search. As stated by Fiske and Taylor (1991), people interpret in- 
formation around them either spontaneously or by recalling the information from their mind.

\section{Discussion and Future Research}

Despite the emergence of technology such as GPS navigation systems either in a car or in mobile phones, people nowadays still refer to physical maps, travel books or street maps. It is true that technology helps to ease the complicatedness of searching for directions in new or unfamiliar areas. However, in my own experience there have been times when I have had difficulty using my mobile phone unless the phone is connected to Wi-Fi or a high cost data plan charges for the use of GPS when abroad. Therefore, I normally print the map of a location that I wish to visit, especially the routes from the point of departure to the final destination. Thus, each person has his/her own way of getting directions if they are lost, even though there are signs placed in city streets to guide pedestrians and motorists.

The signs in Glasgow presented in this paper vary from informational signposts (street maps), advertisements to regulated traffic signs. In the observations, it was discovered that most of the traffic signs were posted with "transgressive notices" (Scollon \& Scollon, 2003) which commonly ranged from graffiti to posted notes. As argued by Scollon and Scollon, these transgressive notices sometimes could only be read by the pedestrians due to the size and placement of the notice. In Figure 8, the "restriction notice for vehicles" was placed on the traffic lights so that it only be noticed by pedestrians who walked past the street. In fact, the notice which was meant for vehicles had been placed on the traffic light to temporarily prohibit use of the "no waiting" and "no loading" zone on Gordon Street at a certain period of time. Because of the way the notice had been positioned, only pedestrians could read it if they happened to be curious.

On the other hand, when examining the Google Maps, it was clear that other transgressive notices were not present on the signs, see Figure 9(b) Google Street View compared to Figure 9(a) which was taken in March 2012 during the study.

Based on the data collected from photographs of the signs, tracked maps, field notes, and video documentations, there are several key findings that can be used for future considerations on the role of traffic signs and also methods of investigation for social scientists. The findings could be used for future upgrading of the technological applications (iPad, or Android apps) as well as for future creative design research in urban studies or visual communication.

Most regulated traffic signs are designed to be used by drivers and not by pedestrians or bicycle riders. The most important element in guiding pedestrians in urban city planning is appropriate positioning and design of street maps and signs. An example of appropriate positioning and street maps for pedestrians are located in London which an implementation of Legible London project.

The paper focuses on walking as part of social practices in urban environments. In Figure 10(a), the sign "no skateboarding" is located in different area and street and thus, the young teenage boys were not breaking any laws as well since it is not against the law to cross the road when it is red. If we are looking at the idea of geosemiotics, the "no skateboarding" was placed on a square which is a common space for youngsters to gather. Thus, since Gordon Street is known for being a busy street with pedestrians going to and from the Central Station, the placement of the "no skateboarding" sign may not be appropriate since there were not many skate-

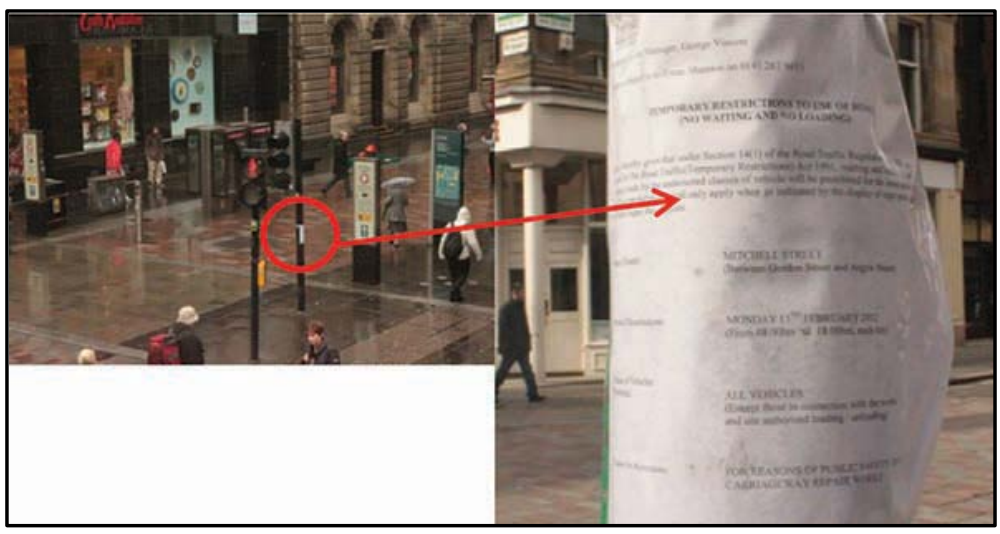

Figure 8. Council “transgressive” notice. 


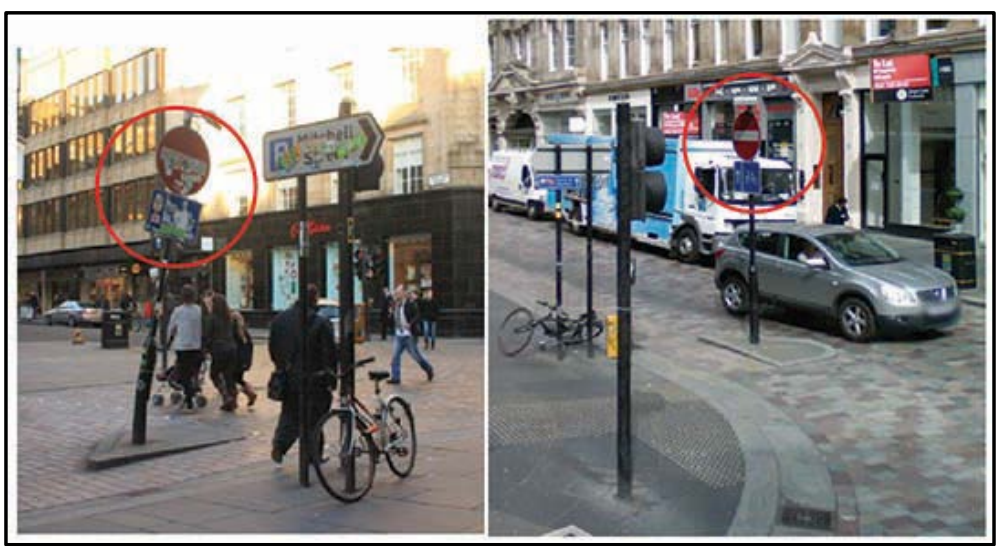

(a)

(b)

Figure 9. (a) Regulated "No entry" and bicycle route ahead sign taken in March 2012 (b) current Google map street view of Gordon Street (image date on Google map is June 2008).

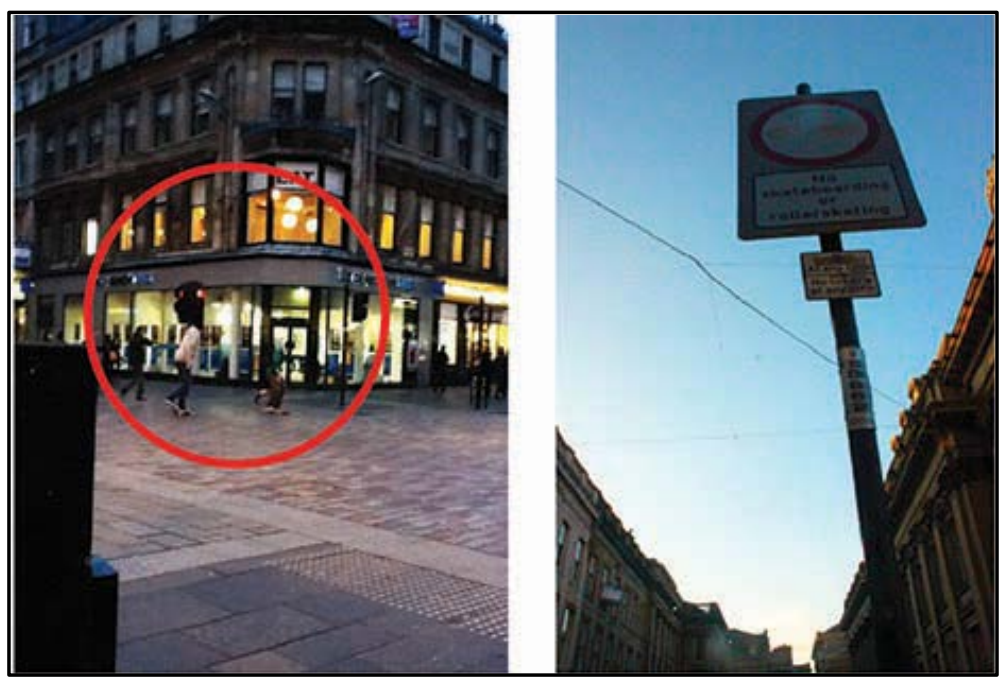

(a)

(b)

Figure 10. (a) Two teenage boys were skateboarding on Gordon Street (b) a "No skateboarding" sign was located at the Royal Exchange Square.

boarders on Gordon Street. Thus, as can be seen in Figure 10(b), the "No skateboarding or roller skating" sign was placed near a square (which is in front of the Museum of Modern Art). It is possible that the placement of the sign is because people use the square as a gathering place especially at night and if there was no sign forbidding skateboarding, teenagers and skaters would probably skateboard on the square.

However, by applying this method of non-participatory observations on site, it was impossible to determine whether the pedestrians or the skateboarders understood the meaning of the signs or whether the signs were placed inappropriately or whether the pedestrians referred to the signs for guidance. Even though several attempts were made to interview pedestrians, the pedestrians either ignored or rejected the requests due to time restraints or the presence of other "interviewers". Having to compete with other "interviewers" i.e. NGOs who interview street pedestrians, limited the applicability of "go-along" interviews suggested by Kusenbach (2003) for phenomenological research in this study. As mentioned by Rapoport (1977), men and women use signs or other physical elements differently. However, during this study, it was not possible to gain any insights into the pedestrians' thought processes when navigating the spaces.

Therefore, in order to get some feedback from the people within the site area, it would have been useful to conduct short interviews with the pedestrians using one of the tenth mobile methods outlined by Büscher, Urry 
and Witchger (2011). The authors suggested that "real places are not necessarily fixed and can be mobile” (p.11). Thus, short interviews were conducted from the top view of the urban context. The researcher interviewed two individuals near the "on site location" instead of "go-along interviews" (Kusenbach, 2003; Anderson, 2004; Carpiano, 2009). Two of the individuals were selected randomly at the EAT cafe (Figure 11(a)) which was located above the observation site location. They were asked several questions related to the traffic signs and how they move around the city. When the participants were asked about the function of signs located on the streets, one of the participants, (Alexander, personal communication, March 6, 2012) stated that:

The signage is more for drivers than it is for pedestrians. Equally, cyclists don't pay a huge amount of atten tion to signage at times. If it says no entry, as a motorist, you won’t go down there. A cyclist may do it because they feel like they're not the same as a motor car. That can be a hazard for pedestrians. I'm only familiar with all the signage because of being a motorist. It's the parking regulars that are more complicated. It doesn't really make sense. You have the smaller signs. People know the double yellows, you can park at all. The double red lines in London - you can park there at all. It's a priority route. It's a little confusing — are you able to park on the double yellows at nighttime? Can you park on a single yellow? It's never made clear. The traffic wardens rely on the fact that people don't know what's going on when they issue tickets (Alexander, personal communication, March 6, 2012).

As mentioned by Alexander, he argued that most road traffic signs are meant to regulate motorists. In Glasgow, there are a lot of parking signs that do not make sense in terms of size. As can be seen in the Figure 11 (b), the parking signs can only be seen by motorists when they are very near to the signs.

Another limitation or drawback of these methods of investigation if only conducted by a single researcher is that they are very time consuming. As mentioned by Hill (1984) tracking pedestrian is "really time consuming and labor intensive”. Technological tools such as DSLR cameras and iPad are significant devices for capturing and recording observational data. However, with the emergence of improved technological devices, there are potential applications for the "Android or Apple" that could help to ease the ethnographers or phenomenologist data collections. Apart from urban design, human behavior, geosemiotics, mobilities and visual communication field of research, the data collected in this study are also useful for computer application developers to design more effective user-friendly applications for future researchers. Thus, since this study also an exploration of the mobile methods used which is considered potential tools for ethnographers and design researchers, there are several advantages and disadvantages that can be identified:

This study not only explores the mobile methods outlined by Büscher, Urry and Witchger (2011) but also testing the relevancies between theoretical views and the practical implications during my empirical study. As can be seen in Table 1, the iPad is a useful tool for mobile methods\# 3, 4 and 6 explorations. However, due to

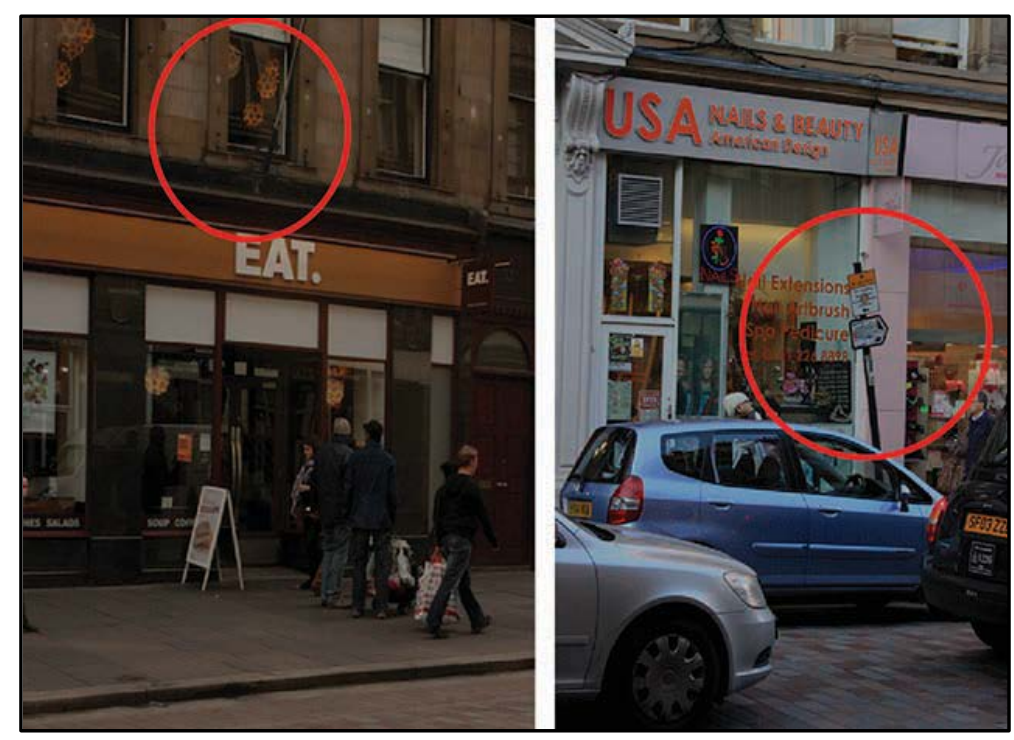

(a)

(b)

Figure 11. (a) Location of interviews at EAT (b) Parking signs that can be seen from the location of interview at Gordon Street. 
Table 1. Advantages and disadvantages of mobile methods and tools used in the study.

\begin{tabular}{ll}
\hline Mobile methods & Advantages \\
\hline Mobile methods\#6: Mobile technologies & $\bullet \quad$ Real-time mapping capability in \\
& tracking movement \\
• Tracking the pedestrians’ movement using & $\bullet \quad$ The application could also track \\
"Road Tripper" application & spaces and bicycle movement within urban $\bullet$ Map used in the application not \\
& $\bullet \quad$ map into JPEG file and upload on but useable. \\
& social media
\end{tabular}

Mobile methods\#3: Mobile video ethnography

“Anticipatory following” video documentation

Mobile methods\#4: Time-space diaries

Using Penultimate and Skitch for note-taking

Mobile methods\#10: Mobile place

Interview conducted in different setting

\begin{abstract}
Capability of taking notes similar to paper-pen methods but with added valued of embedded photos while writing the notes in real-time
\end{abstract}

Documenting real-time movement of pedestrian
- $\quad$ The recorded video are not in good quality especially the ones that were recorded while moving

- $\quad$ The outcome of recorded videos are portrait orientation which limited the view of the background environment

The application only used for researcher's note taking but not for respondents

The EAT location is a café and therefore decrease the participations from the customers

massive applications on the net, the researcher had to be selective in terms of the appropriateness of using the right application.

However, what are the main contributions of this paper? This paper helps to determine the natural behavior of pedestrians in their daily life through direct non-participant observations. From a methodological perspective, the mobile methods proved to be a valuable tool in urban space research. In fact, the "mobile technology" tool used can be a really significant instrument which can be used by all ethnographers if the applications are enhanced and developed further. The free tracking application (Road Tripper) on the iPad showed a potential way of tracking the "real-time” routes made by pedestrians. The experience of tracking the pedestrian's movement discreetly also improves the data compared to participant observation tracking which the observers might influences the data. This can be seen through the nature of human behavior when being observed and tendencies to react differently (Schwartz \& Schwartz, 1955).

\section{Conclusion}

In conclusion, how pedestrians navigate within urban spaces depends on the way they communicate and interact with the environment according to their social needs. Therefore, an additional research method was needed to understand why and what people think and the relationship between the signs and place in a more dynamic approach and setting. Thus, in another stage of my $\mathrm{PhD}$ research methodology, multi methods of qualitative inquiry through focus group interviews were conducted to get some perceptions from individuals on their behavior towards the traffic signs. In addition, the method also used several approaches in terms of tools to investigate people's perceptions of their daily life practices. Consequently, new knowledge of qualitative data collections can be useful for creative design researchers who intend to broaden their options of conducting field research.

\section{References}

Anderson, J. (2004). Talking Whilst Walking: A Geographical Archaeology of Knowledge. Area, 36, 254-261.

http://dx.doi.org/10.1111/j.0004-0894.2004.00222.x 
Baers, R. L. (1966). A Study of Orientation. Unpublished B. Arch. Thesis, California: Berkeley University of California.

Bechtel, R. B., Marans, R. W. and Michelson, W. (1987). Observation: The World under a Glass. In R.B. Marans, \& W. Michelson (Eds.), Methods in Environmental and Behavioral Research (pp. 11-40). New York: Van Nostrand.

Borowsky, A., Shinar, D., \& Parmet, Y. (2008). The Relation between Driving Experience and Recognition of Road Signs Relative to Their Locations. Human Factors: The Journal of the Human Factors and Ergonomics Society, 50, 173. http://dx.doi.org/10.1518/001872008X288330

Büscher, M. (2006). Vision in Motion. Environment and Planning A, 38, 281-299. http://dx.doi.org/10.1068/a37277

Büscher, M., \& Urry, J. (2009). Mobile Methods and the Empirical. European Journal of Social Theory, 12, 99-116. http://dx.doi.org/10.1177/1368431008099642

Büscher, M., Urry, J., \& Witchger, K. (2011). Mobile Methods. Oxon, UK: Routledge.

Carmona, M., Heath, T., Oc, T., \& Tiesdell, S. (2010). Public Places-Urban Spaces: The Dimensions of Urban Design. Burlington: Architectural Press, Elsevier.

Carpiano, R. M. (2009). Come Take a Walk with Me: The “Go-Along” Interview as a Novel Method for Studying the Implications of Place for Health and Well-Being. Health \& Place, 15, 263-272. http://dx.doi.org/10.1016/j.healthplace.2008.05.003

Casey, E. S. (2001). Body, Self and Landscape. In P. C. Adams, S. Hielscher, \& K. E. Till (Eds.), Textures of Place: Exploring Humanist Geographies (pp. 403-425). Minneapolis, MN: University of Minnesota Pres.

Cresswell, T. (2010) Mobilities I: Catching up. Progress in Human Geography, 35, 550-558. http://dx.doi.org/10.1177/0309132510383348

Cullen, G. (1996). The Concise Townscape. Oxford: Architectural Press.

Crundall, D., \& Underwood, G. (2001). The Priming Function of Road Signs. Transportation Research Part F: Traffic Psychology and Behaviour, 4, 187-200. http://dx.doi.org/10.1016/S1369-8478(01)00023-7

Cullen, G. (1961). Townscape. London: Architectural Press.

De Certeau, M. (1984). The Practice of Everyday Life. Berkeley and Los Angeles, CA: University of California Press.

Duff, C. (2010). On the Role of Affect and Practice in the Production of Place. Environment and Planning D: Society and Space, 28, 881-895. http://dx.doi.org/10.1068/d16209

Edquist, J. (2008a). The Effects of Visual Clutter on Driving Performance. Unpublished Ph.D. Thesis, Melbourne: Monash University.

Factsheets (2012). http://www.glasgow.gov.uk/index.aspx?articleid=3014

Fauque, R. (1986). A New Semiological Approach to the City. In M. Gottdiener, \& A. P. Lagopoulos (Eds.), The City and the Sign: An Introduction to Urban Semiotics (p. 145). New York: Columbia University Press.

Fiske, S. T., \& Taylor, S. E. (1991). Social Cognition. New York: McGraw-Hill.

Golledge, R. G., \& Stimson, R. J. (1997). Spatial Behavior: A Geographic Perspective. New York: The Guilford Press.

Halprin, L. (1963) Cities. New York: Reinhold Publishing Corporation.

Hamid, S. A., Jensen, O. B., \& Andrade, V. (2012). Signs in Place: Choreographing Travel Flow in Urban Spaces. Spaces and Flows: An International Journal of Urban and ExtraUrban Studies, 2, 115-128.

Hill, M. R. (1984). Stalking the Urban Pedestrian a Comparison of Questionnaire and Tracking Methodologies for Behavioral Mapping in Large-Scale Environments. Environment and Behavior, 16, 539-550.

Jensen, O. B. (2013). Staging Mobilities. International Library of Sociology. London: Routledge.

Jensen, O. B. (2010a). Negotiation in Motion: Unpacking a Geography of Mobility. Space and Culture, 13, 389-402. http://dx.doi.org/10.1177/1206331210374149

Jensen, O. B. (2010b). Embodied Cultures of Mobilities. The 6th International Cosmobilities Conference "Cultures of Mobilities: Everyday Life, Communication, and Politics”, Aalborg, 27-29 October 2010, 1-26

Knox, P. L., \& Pinch, S. (2006). Urban Social Geography: An Introduction. Essex: Pearson Education Limited.

Kusenbach, M. (2003). Street Phenomenology: The Go-Along as Ethnographic Research Tool. Ethnography, 4, $455-485$. http://dx.doi.org/10.1177/146613810343007

Lee, J., \& Ingold, T. (2006). Fieldwork on Foot: Perceiving, Routing, Socializing. In S. Coleman, \& P. Collins (Eds.), Locating the Field: Space, Place and Context in Anthropology (pp. 67-86). Palo Alto, CA: Ebrary.

Li, C. (2006). User Preferences, Information Transactions and Location-Based Services: A Study of Urban Pedestrian Wayfinding. Computers, Environment and Urban Systems, 30, 726-740.

http://dx.doi.org/10.1016/j.compenvurbsys.2006.02.008

Lynch, K. (1960). The Image of the City. Vol. 11, Cambridge, MA: MIT Press. 
Millonig, A., Brändle, N., Ray, M., Bauer, D., \& van der Spek, S. (2009). Pedestrian Behaviour Monitoring: Methods and Experiences. In B. Gottfried, \& H. Aghajan, (Eds.), Behaviour Monitoring and Interpretation BMI: Smart Environments, Volume 3 of Ambient Intelligence and Smart Environments (pp. 11-42). Amsterdam: IOS Press.

Pettersson, R., \& Zillinger, M. (2011). Time and Space in Event Behaviour: Tracking Visitors by GPS. Tourism Geographies, 13, 1-20.

Rapoport, A. (1977). Human Aspects of Urban Form. Oxford: Pergamon.

Schwartz, M. S., \& Schwartz, C. G. (1955). Problems in Participant Observation. American Journal of Sociology, 60, 343354. http://dx.doi.org/10.1086/221566

Scollon, R., \& Scollon, S. W. (2003). Discourse in Place: Language in the Material World. London: Routledge. http://dx.doi.org/10.4324/9780203422724

Sheller, M. (2012). Mobilities. In The Wiley-Blackwell Encyclopedia of Globalization. Oxford: Blackwell Publishing Ltd. http://dx.doi.org/10.1002/9780470670590

Sheller, M., \& Urry, J. (2006). Mobile Technologies of the City. New York: Routledge.

Shoval, N. (2008). Tracking Technologies and Urban Analysis. Cities, 25, 21-28. http://dx.doi.org/10.1016/j.cities.2007.07.005

Simmel, G. (1950). The Metropolis and Mental Life. In K. H. Wolff (Ed.), The Sociology of Georg Simmel (pp. 409-424). New York: The Free Press.

Solnit, R. (2001). Wanderlust. A History of Walking. London: Verso.

Urry, J. (2007). Mobilities. Cambridge: Polity.

Van der Spek, S., Van Schaick, J., De Bois, P., \& De Haan, R. (2009). Sensing Human Activity: GPS Tracking. Sensors, 9, 3033-3055. http://dx.doi.org/10.3390/s90403033

Vannini, P. (2012). Ferry Tales: Mobility, Place, and Time on Canada's West Coast. New York: Routledge.

Vertesi, J. (2008). Mind the Gap: The London Underground Map and User’s Representations of Urban Space. Social Studies of Science, 38, 7-33. http://dx.doi.org/10.1177/0306312707084153

Whyte, W. H. (1994). City: Rediscovering the Center. New York: Doubleday. 
Scientific Research Publishing (SCIRP) is one of the largest Open Access journal publishers. It is currently publishing more than 200 open access, online, peer-reviewed journals covering a wide range of academic disciplines. SCIRP serves the worldwide academic communities and contributes to the progress and application of science with its publication.

Other selected journals from SCIRP are listed as below. Submit your manuscript to us via either submit@scirp.org or Online Submission Portal.
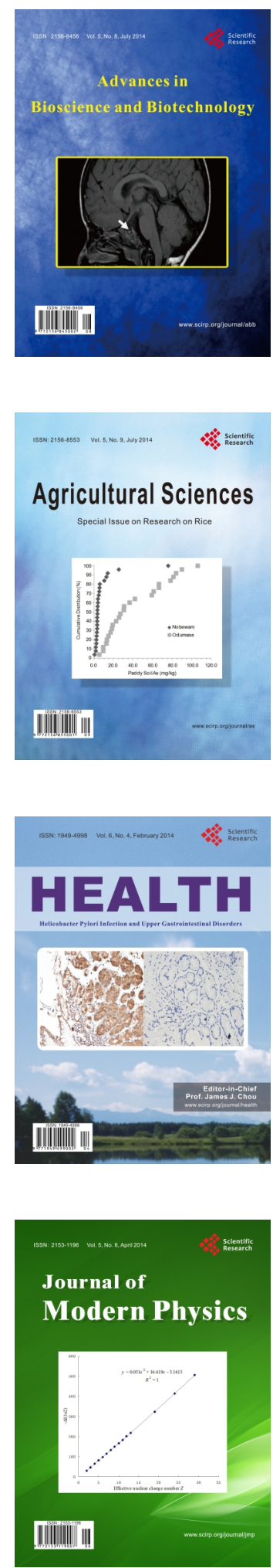
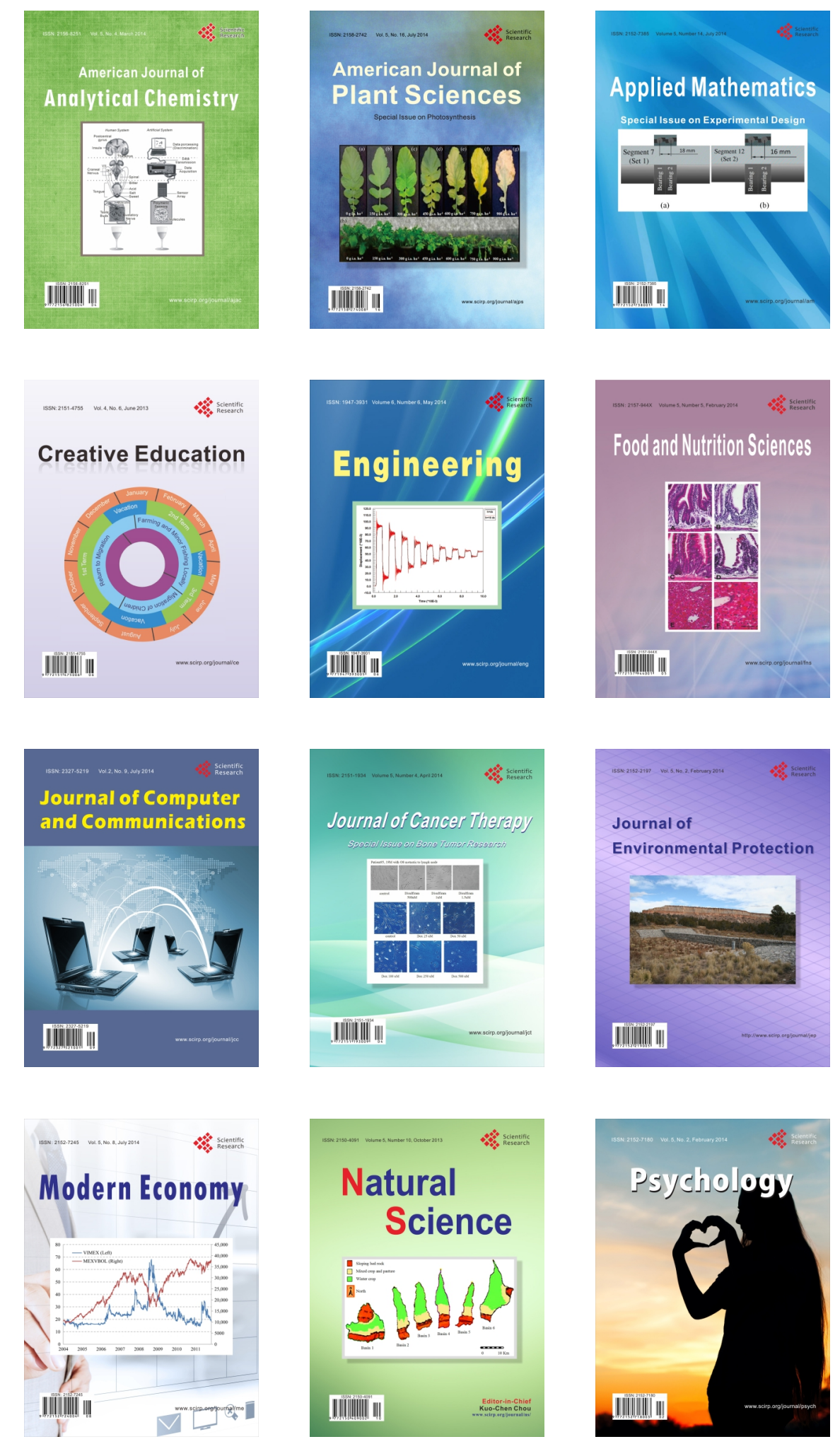